\title{
Tiempo, arte y sociedad a finales del siglo XVIII neogranadino. Los comienzos tardíos de la modernidad ilustrada
}

\section{Time, Art and Society Neogranadino Late Eighteenth Century. Late Starts of Enlightened Modernity}

\author{
Renán Silva ${ }^{1}$ \\ Universidad de los Andes (Colombia)
}

Recibido: 06-02-17

Aprobado: 17-02-17

\section{Resumen}

El presente texto señala un conjunto de hechos que indica el proceso en marcha de separación cultural entre los nuevos hombres de letras, los llamados "criollos ilustrados" - aficionados a la historia natural-, y el conjunto de la sociedad: tanto los grupos sociales dominantes defensores de la tradición, como la sociedad popular - urbana y rural-, en el Virreinato de Nueva Granada a finales del siglo XVIII, e intenta mostrar las condiciones de ese proceso de "distancia cultural creciente", poniendo de presente que tal proceso, producto de la propia evolución cultural, no constituye ninguna rareza y ha estado presente en muchas otras sociedades y épocas, y debe ser reconstruido y analizado más allá de todo juicio de valor.

Palabras-clave: Francisco José de Caldas, arte, cultura, historia.

\footnotetext{
${ }^{1}$ (rj.silva33@gmail.com). Sociológo y Doctor en Historia por la Université de Paris I - (Pantheon - Sorbonne) y Postdoctorado en la Universidad de Oxford. Entre sus publicaciones recientes están: Cuestiones Disputadas. Ensayos sobre Marx, Freud, Foucautl Bourdieu Bloch (Bogotá, Uniandes, 2016), Cultura escrita, historiografia y sociedad en el virreiinato de la Nueva Granada. Nuevas perspectivas de análisis sobre el Papel periódico de Santafé de Bogotá, 1791-1797, (Medellín, La Carreta editores, 2015) Lugar de dudas. Sobre la práctica del análisis histórico (Bogotá, Uniandes, 2014)
} 


\begin{abstract}
The present text indicates a set of facts indicating the process underway of cultural separation between the new men of letters, called "creoles illustrated" - fond of natural history- and the whole of society: the dominant social groups defenders of tradition, as well as society people -urban and rural- in the Viceroyalty of New Granada at the end of the 18th century, and tries to show the conditions of the process of "growing cultural distance", putting this that such a process, product of the cultural evolution, does not constitute no rarity and has been present in many other societies and times, and must be reconstructed and analyzed beyond all value judgment.
\end{abstract}

Key-words: Francisco José de Caldas, Art, Culture, History.

\title{
Contenido argumental y dirección principal de estas páginas
}

Los Ilustrados neogranadinos fueron críticos radicales de la cultura de su sociedad y de su época y expresaron en muchas oportunidades su desazón ante lo que estimaban como rutina, repetición, falta de creatividad y sometimiento reverencial a la tradición que les parecía que caracterizaba a su sociedad ${ }^{2}$.

El "descontento ilustrado" era con el conjunto de la sociedad, con sus valores y aspiraciones. Su crítica se dirigía tanto a los sectores nobles de las generaciones anteriores -en general sus padres y abuelos-, como a aquellos grupos sociales que designaban como plebeyos, y a los que en el lenguaje nuestro designaríamos hoy como grupos populares - de manera básica indios, mestizos, mulatos y negros-. La actitud crítica se extendía a casi todas las esferas de la vida social, desde las formas rutinarias de la agricultura y de las artes aplicadas, hasta el campo de la producción de imágenes o de las prácticas religiosas, pasando por lo que rechazaban como una "falta de civilidad" de sus contemporáneos, por relación con el entorno urbano, los cuidados del cuerpo y la salud, y las formas del trato cotidiano. Desde ese punto de vista habría que decir que el reducido grupo de los jóvenes letrados -ya no tan jóvenes a finales

\footnotetext{
${ }^{2}$ Sobre la Ilustración y sobre el grupo de los Ilustrados en el Nuevo Reino de Granada (grosso modo la actual Colombia) cf. Renán Silva, La Ilustración en el Virreinato de la Nueva Granada. Estudios de historia social y cultural. Medellín La Carreta Editores, 2005, y R. Silva, Los Ilustrados de Nueva Granada, 1760-1808. Genealogía de una comunidad de interpretación [2002] Medellín, Banco de la República/EAFIT, 2008 -segunda edición-. Sobre el periodo anterior a la Ilustración en el plano de las culturas académicas, con cierta falta de énfasis explícitos sobre la cultura social de la época, que aparece más como telón de fondo y condición de posibilidad, R. Silva, Saber, Cultura y Sociedad en el Nuevo Reino de Granada. Siglos XVII y XVIII [1984]. Medellín, La Carreta Editores, 2012. Estas obras, que son el cuadro de referencia de nuestro trabajo y que son fáciles de consultar, nos liberan de convertir el texto en un conjunto de citaciones y referencias multiplicadas que oscurecen lo que nos parece central en este ensayo: su argumento.
} 
del siglo XVIII- caracterizados como los representantes de la Ilustración, había asumido buena parte del ideario predicado por los hombres de letras de la Monarquía en el periodo de los Borbones, lo que exige, entre otras cosas, no perder de vista la crítica que la monarquía misma había hecho de su pasado, y de manera particular del carácter improductivo de algunas de sus "colonias" (como se comenzará a decir en adelante en el Consejo de Indias), caso en el cual se incluía al Nuevo Reino de Granada ${ }^{3}$.

Detrás de esa crítica general, aunque muy pocas veces estridente y gritona, parece encontrarse una toma de distancia y un desencanto frente a los valores y a las aspiraciones de esa sociedad, y frente a la mayor parte de sus formas de hacer y de pensar, aunque los Ilustrados - los nuevos hombres de letrasseguían participando enteramente de las dos formas básicas de cohesión social en esa sociedad: la creencia profunda en la religión católica, en los valores del cristianismo y en la Iglesia de Roma, y la aceptación sin ninguna duda de la legitimidad de la monarquía, por más que hayan discrepado de las políticas de la Corona y de sus ministros en algunos momentos particulares ${ }^{4}$.

Desde el punto de vista de las relaciones entre cultura y sociedad, los Ilustrados neogranadinos vuelven a poner de presente que la crítica de la cultura de una sociedad separa de esa sociedad, y de manera muy precisa que esa crítica crea una zona de sombras y de malentendidos, que interfiere una comunicación que en momentos anteriores resultaba posible. De manera particular el historiador puede constatar la dificultad de "diálogo" con los grupos populares, una situación que no deja de entrañar cierto dramatismo, por cuanto una de las aspiraciones del pensamiento ilustrado, en todas partes en donde hizo su aparición, era la difusión del conocimiento y la educación del "común", aboliendo muchas de las barreras que habían sido características de las sociedades tradicionales. Como se debe recordar, una de sus aspiraciones

\footnotetext{
${ }^{3}$ Cf. en general Germán Colmenares -Editor-, Relaciones de Mando e Informes de los virreyes de Nueva Granada -3 tomos-. Bogotá, Banco Popular, 1989. Las Relaciones dejan claro, que desde 1740, pero con más énfasis y resolución después de 1760, la Corona busca orientar por un camino distinto al pobre e improductivo Nuevo Reino de Granada. Crear un virreinato es parte central de la estrategia. Hay que advertir que, desde luego, la reorientación imperial cobija al conjunto de las posesiones imperiales hispanas en ultramar. Cf. por ejemplo John H. Elliott, Imperios del mundo atlántico. España y Gran Bretaña en América (1492-1830. Madrid, Taurus, 2006 -cf. sobre todo capítulos 9,10 y 11.

${ }^{4}$ Es conocida la tendencia de la historiografía nacionalista en América latina a convertir la más débil discrepancia o aspiración de los llamados "criollos" hispanoamericanos en un antecedente de las revoluciones nacionales posteriores a 1808. Para el caso colombiano una buena síntesis de la teleología nacionalista resulta ser Javier Ocampo López, El proceso ideológico de la emancipación. Las ideas de génesis, independencia, futuro e integración en los orígenes de Colombia [1974]. Bogotá, Editorial Planeta, 1999. La crítica rigurosa y comprensiva de este punto de vista -ya un lugar común historiográfico- es la de François-Xavier Guerra, Modernidad e independencias. Ensayos sobre las revoluciones hispánicas. Madrid, MAPFRE, 1992. En el registro estricto de los imaginarios políticos sobre las revoluciones de Antiguo Régimen en el caso del Nuevo Reino de Granada continúa siendo muy importante la lectura de la obra ejemplar de John Leddy Phelan, El pueblo y el rey: la revolución Comunera en Colombia, 1781 [1974]. Bogotá, Carlos Valencia Editores, 1980.
} 
en el plano de la sociedad, era la de involucrar a los grupos populares en el proceso de cambio social y cultural que trataba de poner en marcha la burocracia ilustrada, que era ya a finales del siglo XVIII un ideario asimilado y apropiado por los Ilustrados, a quienes desde los años 1770 la Monarquía había incluido en su proyecto de reforma y había designado como "la juventud noble del reino" y había impulsado y promocionado, hasta la crisis de 1790, cuando los intereses sociales y culturales de la "joven nobleza del reino" parecen tomar un camino y un grado de autonomía que los pone en ocasiones en "contradicción" con la monarquía y la burocracia local - un hecho fácil de constatar cuando se leen con cuidado sus principales publicaciones, sobre todo periodísticas, en donde se concretó buena parte de los ideales de difusión cultural de los neogranadinos ilustrados ${ }^{5}$.

Me parece que ese desencuentro o zona de sombras y malentendidos entre una "sociedad determinada" y sus "hombres de letras", un problema clásico de la sociología y la historia de la vida intelectual, merece ser interrogado, sobre todo tratándose del caso de los pensadores Ilustrados y de la Ilustración, por cuando éstos y aquella aspiraron a introducir en la vida social un ruptura radical con su apelación a la crítica y con el intento de uso sistemático de ese instrumento de la modernidad, considerado como un valor y actitud superiores de conocimiento, valor y actitud que especificaban precisamente lo que se consideró por parte de sus promotores como el signo mismo de los tiempos nuevos ${ }^{6}$.

Podemos intentar ese análisis, pero para ello debemos evitar el camino de las grandes generalizaciones, de las formulaciones abstractas que dejan por fuera cualquier consideración de tiempo y espacio, y más bien construir un pequeño estudio de caso -un caso posible de lo real, diría Gaston Bachelard-, considerando algunos textos del ilustrado neogranadino Francisco José de Caldas $^{7}$, textos a partir de los cuales podemos intentar explorar, de manera particular, esa dificultad que hemos enunciado de forma general, y que se puede

\footnotetext{
${ }^{5}$ Cf. Por ejemplo R. Silva, Prensa y Revolución. Bogotá, Banco de la República, 1988.

6 Sobre esta perspectiva de análisis y sobre la propia definición de la Ilustración como actitud crítica cf. la recopilación de textos de Michel Foucault, Sobre la Ilustración. Madrid, Tecnos Clásicos del pensamiento-, 2003 -no resulta ningún anacronismo recurrir a los espléndidos textos de Foucault sobre este punto, pues son textos que sacan el problema del atolladero de las definiciones temática y cronológicamente estrechas, que terminarán siempre declarando la Ilustración como un proceso "europeo"-. Para una visión puramente temática y de sobrevuelo, aunque útil dentro de esa limitación, cf. Tzevetan Todorov, El espíritu de la Ilustración. Barcelona, Círculo de Lectores / Galaxia Gutenberg, 2008. En el propio virreinato de Nueva Granada el más incisivo "heraldo" de la crítica y de la idea de un "tiempo de la Ilustración", resulta ser el periódico de breve duración Correo Curioso, erudito, económico y mercantil de la ciudad de Santafé de Bogotá. 1801.

7 A pesar de ser uno de los más destacados miembros del panteón científico y patriótico nacional, no son buenas ni frecuentes las biografías de Francisco José de Caldas. Sobre Caldas, una obra digna y aun legible, que no es desde luego una biografía, es la compilación, Caldas -1768-1816. Bogotá, Molinos Velásquez Editores, 1994, que presenta un enfoque variado entre el nacionalismo mitológico habitual y el análisis histórico moderno.
} 
especificar como el caso de un grupo de jóvenes de letras en pleno proceso de trasformación cultural, rumbo a la "modernidad", viviendo en una sociedad que no es moderna en absoluto, ni desde el punto de sus relaciones sociales, ni desde el punto de vista de su cultura social ${ }^{8}$.

La documentación histórica del problema enunciado indica de manera clara que los Ilustrados neogranadinos encontraron en su sociedad barreras y resistencias, que concretaban un hecho real -no puramente imaginario-: la dificultad para hacerse escuchar y comprender por parte de quienes deseaban que fueran sus interlocutores. De un lado la generación anterior de hombres de letras. De otro lado los sectores que hoy designaríamos como populares, entre quienes deseaban circular y difundir lo que consideraban como la "buena nueva" del mundo moderno; una dificultad que parece remitir a la desigualdad en el cambio (siempre acelerado cuando se trata de colmar "retrasos"), en este caso por partida doble, pues se trataba de que los propios promotores de la Ilustración se pusieran ellos mismos al día con su "ideario", y de otro que avanzaran en el proceso de difusión de las ideas y comportamientos prácticos de los que esperaban la reforma de la sociedad ${ }^{9}$.

En un plano más general que el de la Historia social -es decir más allá del proceso histórico concreto en torno del cual construimos nuestro caso de reflexión-, avanzando hacia el campo del análisis sociológico de la modernidad, la situación de los Ilustrados que acabamos de indicar en el párrafo anterior, parece ponernos de presente uno de los rasgos distintivos de lo que a veces se ha denominado como la tragedia de la cultura moderna, el hecho de que la cultura separa y divide, introduce una discontinuidad, que luego se tornará insuperable, en lo que antes aparecía como una comunidad unificada en una cosmovisión, en una mirada compartida sobre el mundo social y el mundo natural, inaugurando una forma de separación social a la que las ciencias sociales ha hecho referencia con los términos de "élites" y "masas", explorando una problemática que, sobre todo en el plano de la cultura intelectual, es la de las sociedades modernas o en camino de serlo, por diferencia con las viejas sociedades tradicionales en las que el aspecto comunitario y compartido de las formas de representación social continua siendo dominante. Los Ilustrados de Nueva Granada recuerdan esos momentos

${ }^{8}$ El marco general de interpretación proviene de Roger Chartier, "Trayectorias y tensiones culturales en una sociedad de Antiguo Régimen", en Jacques Revel y André (directores), Histoire de la France, T. III. Les formes de la culture. Paris, Seuil, 1987. Para la idea de la construcción de un "estudio de caso" cf. Jean-Claude Passeron/ Jacques Revel, "Penser Par Cas", Enquête, No 4., Paris, EHESS, 2005.

${ }^{9}$ José María Portillo ha mostrado con pertinencia que la política ilustrada (y de los ilustrados) no es la política revolucionaria, sino la reforma social, es antes la "sociedad" y la "economía" que el poder político. En ese programa de reformas, que es el de la monarquía, pondrán sus esperanzas los Ilustrados, quienes harán de ellas el centro de su ideario. Cf. J. M. Portillo, "Política", en Vincenzo Ferrone y Daniel Roche, Editores, Diccionario Histórico de la Ilustración. Madrid, Alianza Editorial, 1998, pp. 112-123.

Araucaria. Revista Iberoamericana de Filosofía, Política y Humanidades, año 19, $\mathrm{n}^{\circ} 38$. Segundo semestre de 2017. Pp. 369-391. ISSN 1575-6823 e-ISSN 2340-2199 doi: 10.12795/araucaria.2017.i38.17 
iniciales de un proceso de diferenciación social y separación cultural que acompaña a nuestras sociedades desde entonces hasta el presente ${ }^{10}$.

En las páginas siguientes, considerando algunos textos del ilustrado neogranadino Francisco José de Caldas, quisiéramos explorar esa dificultad de un grupo cultural en formación, para hacerse escuchar y comprender, y la emergencia de ese proceso de separación que hemos mencionando.

\section{Los relatos de viaje de Francisco José de Caldas}

La actividad viajera de Caldas en apariencia es, términos generales, más o menos conocida. Por fuera de sus viajes entre Popayán y Santafé, en la época en que fue estudiante de jurisprudencia en la capital del virreinato, se trata de dos "ciclos" de viaje, en verdad no lo suficientemente estudiados, pero al parecer notables para acercarse al problema que más nos interesa en estas páginas ${ }^{11}$.

El primero de esos ciclos de viaje - en la década final del siglo XVIIIconduce a Caldas desde Popayán a poblaciones cercanas (que hoy son parte de los Departamentos de Cauca y del Huila en la actual Colombia). Viaja como comerciante, en compañía de uno de sus hermanos y de un indio que conduce las mulas, según el mismo lo cuenta, y vende baratijas en las ferias dominicales, es decir, en los días tradicionales de mercado, en pequeños pueblos polvorientos, que tienen esas ferias como sus únicos momentos de animación. Los demás días de la semana se dedica a la lectura y a la observación, a la exploración del territorio, siendo en ese momento un hombre de letras en periodo de formación, tratando de instruirse en los campos de la astronomía, la geografía y la botánica (para utilizar sus propias clasificaciones).

En esta época temprana de su actividad de "explorador científico", Caldas hace por lo menos dos mapas - carta en el lenguaje de la época- de las poblaciones que visita - los de las localidades vecinas de Timaná y La Plata-, contratado por sus cabildos, que quieren conocer los límites de sus jurisdicciones, uno de los grandes problemas políticos-espaciales en esa sociedad, y fuente constante de disputas y litigios ${ }^{12}$. Es la época en que

${ }^{10}$ Con cierta seguridad se puede afirmar que la exploración de los procesos de diferenciación cultural a partir de patrimonios comunes, realizada para el caso de los Estados Unidos por Lawrence Levine, en Highbrow/Lowbrow. The Emergence of Cultural Hierarchy in America. Harvard University Press, 1988, es una de las mayores contribuciones en este campo de la historia cultural.

11 Sobre el viaje ilustrado puede verse, como simple introducción Vincenzo Ferrone y Daniel Roche, Editores, Diccionario Histórico de la Ilustración, op. cit., -"Viajes", pp. 287-294. Sobre el viaje de letras de los Ilustrados neogranadinos cf. Silva, Los Ilustrados, op. cit., para observar dos experiencias diferentes de viaje: la del exilio político y la iniciación en la ciencia en Europa, y la del viaje del explorador científico, recorriendo su propia sociedad inmediata. pp. 133 y ss.

12 Más allá de esta observación incidental, hay que citar el importante libro de Mauricio Nieto Olarte [et al.], La obra cartográfica de Francisco José de Caldas. Bogotá, Universidad de los Andes/ CESO/ICANH/, 2006. 
Caldas ha roto con toda ilusión de ser jurista o profesor, y está tratando de ganarse la vida como mercader -como pequeño comerciante-, al tiempo que avanza en su proceso de formación científica, mientras que va realizando experimentos con el barómetro y el termómetro. Es un periodo fecundo y exaltado en su proceso de formación, tal como lo deja ver su actividad epistolar de esos años ${ }^{13}$.

El segundo ciclo de viajes de Caldas, algo mejor conocido, y al parecer más importante que el primero, va aproximadamente de mediados de 1802 hasta finales de 1805, y tiene como epicentro el Reino de Quito. Es una época en que se siente más afirmado como hombre de ciencia, pues cree haber hecho un descubrimiento (sobre la medición de alturas), ha entrado en relación con José Celestino Mutis, quien se ha convertido en su mentor, y viene de ilusionarse y enseguida desilusionarse con su admirado Barón de Humboldt, quien luego de conocerlo, trabajar unos días con él en asuntos de astronomía y de botánica, y habiendo reconocido los indudables talentos de Caldas como investigador, rechaza la posibilidad de que el neogranadino lo acompañé en la continuación de su viaje, prefiriendo viajar el gran científico alemán en compañía de un joven noble quiteño, en quien se interesaba por razones que no son del caso explorar ahora ${ }^{14}$.

El viaje de Caldas a partir de 1802, ya rota toda ilusión de poder explorar una parte del Continente con el Barón de Humboldt es, pues, en parte, compensatorio y se inscribe, en principio, en una perspectiva de pérdida, de duelo, y tuvo objetivos mucho más modestos que el diseño original, pues el viaje fue sometido por sus mecenas, José Celestino Mutis y José Ignacio de Pombo, a un drástico recorte desde el punto de vista de sus objetivos de ciencia, al parecer por razones de recursos económicos-. Pero a pesar de todas las dificultades se trató de un viaje muy importante para sus investigaciones, y para su escritura, las que se alimentan de manera permanente con esos desplazamientos por el Reino de Quito, lo que finalmente le permitirá entrar en 1805 a Santafé y

${ }^{13}$ En el fondo, la época viajera de Caldas, que es una parte central de su trabajo de ciencia, es poco conocida, pues todos los investigadores nos remitimos sin mayores discusiones a la misma fuente: su nutrida y expresiva correspondencia, pero no hemos avanzado en la localización de los registros que permitirían contrastar la visión de los hechos que presenta y glosa Caldas. Así por ejemplo, es posible que un trabajo cuidadoso en los archivos municipales de las poblaciones que recorría en este primer ciclo de viajes, nos permita saber más sobre las condiciones económicas y de propiedad de derechos de autor bajo las cuales aceptó elaborar los mapas que se le solicitaron, dos inquietudes que lo asaltaron por muchos años y que tendrán un desenlace importante a principios del siglo XIX, en sus negociaciones con el virrey en torno a la elaboración "de la carta del Reyno". Cf. Silva, Los Ilustrados, op. cit., pp. 593-611. Para la correspondencia Academia Colombiana de Ciencias Exactas, Físicas y naturales, Cartas de Caldas. Bogotá, Imprenta Nacional, 1978.

${ }^{14}$ Enrique Pérez Arbeláez, Humboldt en Colombia [1959]. Bogotá, COLCULTURA, 1982, sigue siendo una guía cronológica y espacial correcta para conocer la trayectoria de Humboldt por el Nuevo Reino de Granada, su encuentro con Caldas y su partida posterior, aunque la presentación es simplista e ingenua. La correspondencia de Caldas recrea muy bien aspectos de este itinerario y le suma la propia emoción de caldas ante el próximo evento y la manera como presentaba la noticia a sus amigos ilustrados más cercanos. 
presentarse ante J. C. Mutis, cargado con un riquísimo herbario y con cientos de páginas redactadas sobre historia y ciencias naturales ${ }^{15}$.

Como ocurre con casi todos los viajeros y exploradores del siglo XVIII, las "Relaciones de viaje" de Caldas son compendios sabios de historia natural, al tiempo que son ricas descripciones etnográficas, que se extienden en consideraciones informativas y analíticas sobre la sociedad que se ha recorrido ${ }^{16}$. En lo que tiene que ver con el análisis de la sociedad y de la cultura de su época, que es lo que de manera particular nos interesa, hay por lo menos cinco direcciones sobre las que es posible preguntarse a partir de los textos de FJC.

1. En el plano más general, Caldas presenta de manera repetida y en diferentes momentos su balance de la sociedad de su época, desde el punto de vista de su "estado de civilización", tanto en las posiciones elevadas de la jerarquía social, como en lo que tiene que ver las comunidades indígenas y mestizas de las zonas que recorrió, poniendo énfasis muy particulares sobre las relaciones sociales y las formas dominantes de interacción social, y haciendo precisas descripciones y agudas críticas sobre las formas como las autoridades locales gobiernan y dirigen la sociedad, con referencias detalladas al papel de curas y corregidores en el mantenimiento del orden social y de un sistema despótico de explotación y dominio.

2. Presenta también Caldas sus apreciaciones sobre los niveles técnicos de esa sociedad, en cuanto al trabajo agrícola y la artesanía, con descripciones de gran detalle, y a veces de gran colorido, en muchas oportunidades acompañando sus observaciones con dibujos de los instrumentos de trabajo -dibujos que el mismo realiza-, comparando con lo que le parecía o sabía que debían ser los instrumentos europeos similares, indicando lo que podría haber de "apropiación singular" en los instrumentos y las formas de trabajo que observa en sus recorridos.

3. El viajero no deja de introducir consideraciones que hoy designaríamos como sociológicas, sobre los elementos de cambio social y cultural presentes en la sociedad, describiendo con aparente buen tino los grupos y actores en donde se concentran las actitudes ilustradas que celebra, caracterizadas por su interés en el progreso, en la educación, en la experimentación agrícola, en la

15 Sobre esos años iniciales del siglo XIX, sobre su trabajo de ciencia mientras viajaba y sobre su retorno a Bogotá cf. la compilación Historia documental de la Real Expedición Botánica del Nuevo Reino de Granada después de la muerte de su director, don José Celestino Mutis, 1808-1852. Bogotá, Instituto de Cultura Hispánica, 1986.

${ }^{16}$ Sobre el viaje de ciencia y el explorador cf. Vincenzo Ferrone, "El hombre científico" y Marie Noëlle Bourguet, "El explorador", en Michel Vovelle y otros, El hombre de la Ilustración [1992]. Madrid, Alianza Editorial, 1995. 
observación de los fenómenos naturales; aunque Caldas pone también su ojo observador igualmente sobre otros grupos de la sociedad - "altos" o "bajos", según las jerarquía sociales de su época-, encontrando en esos grupos sociales inercias culturales y actitudes de resistencia que se oponían al cambio de la sociedad, indicando su parecer sobre el gran peso que en la sociedad tenían tales grupos "tradicionalistas", que le parecían ser la fuerza dominante de la sociedad. Caldas realiza comparaciones con el pasado -casi siempre se remite al momento de la Expedición franco-española de 1735, que buscaba aclarar el problema de la "redondez de la tierra"-, y se permite afirmar que, por comparación con el estado cultural dominante medio siglo antes, a pesar de las resistencias la sociedad ha entrado en un tiempo nuevo, el tiempo de la Ilustración.

4. Las "Relaciones de viaje" de Caldas informan con gran cuidado y de manera reiterada sobre las formas de habitar y de poblar, de modelar el espacio social, lo que se concreta en sus observaciones sobre las formas de construir, es decir en su balance de la "arquitectura" que encuentra a su paso por las zonas que visita, entendiendo aquí por arquitectura tanto las construcciones civiles, como religiosas, y los entornos domésticos inmediatos en que habita la gente: las casas, los muebles, las cocinas, mencionando en muchas ocasiones la transformación humana del paisaje, mediante el trabajo: construcción de puentes, preparación de suelos, formas de siembra, cosecha y recolección dejando la idea de una sociedad andina de gran dinamismo y complejidad, en donde se combinan tiempos diferentes del acontecer social.

5. Su evaluación del arte en esas sociedades, concretada en el estado de las iglesias y otros lugares de culto, y en la producción artística religiosa y profana -en general la pintura y la escultura-. Posiblemente sobre este punto quinto sea sobre el que menos habla Caldas, pero lo que dice es claro y explícito, expresando juicios que presentan lo que parece ser la mirada crítica ilustrada sobre la actividad artística de la sociedad, una "mirada" que cuando se combina de manera prudente con sus otras observaciones sobre las formas de poblar, construir y habitar, deja ver los límites de su crítica, pero también sus aciertos.

Los relatos de viaje de Caldas considerados en conjunto dejan al final en el lector una imagen de síntesis de lo que puede haber sido la visión ilustrada de la cultura y de la sociedad de su época, y permiten entender muchas de las razones de la crítica que propusieron los nuevos hombres de letras de la segunda mitad del siglo XVIII. Leyendo esas páginas es posible acercarnos a ese proceso de ruptura social y cultural que se encuentra presente en sus descripciones y que en nuestra opinión es constitutivo de la formación 
de la cultura y sociedad modernas, entendido este proceso en el sentido de surgimiento de nuevas relaciones sociales, de nuevas maneras de interacción con la naturaleza, de nueva formas de pensar y percibir el tiempo, el vínculo social, y la posibilidad de nuevos futuros posibles que antes no aparecían en la consideración de las gentes de letras y de cultura.

Se podría decir que se trata de manera básica de ese proceso que, sobre la base de una síntesis de la experiencia europea de paso del feudalismo a la moderna sociedad industrial, la sociología de principios del siglo XX, especificó como el paso de inicial de la comunidad a la sociedad, o de las solidaridades orgánicas a las mecánicas, sin que se pueda valorar esa imagen del tránsito de un sector de las sociedades europeas como la única posible, o como un "modelo típico de evolución" que todas las sociedades deberían reproducir"17.

Esas formas de "categorizar" la vida social a las que aludimos como "tipologías polares" son ante todo una guía de trabajo, para pensar un problema del "cambio social", un proceso innegablemente presente en las sociedades hispanoamericanas de la segunda mitad del siglo XVIII, un proceso anterior a las independencias nacionales, y que muestra rasgos de evolución en dirección de lo que se designa como una sociedad de individuos, tanto en el sentido de Louis Dumont, como en el de Norbert Elias - dejando aquí de lado las diferencias visible entre esos dos autores-, por más que tal proceso se encuentre solamente en sus fases iniciales, y que haya mostrado caminos tan sinuosos en los siglos XIX y XX. Se trata, en suma, del comienzo de una modificación en las formas de interdependencia social. Se trata de una alteración en la forma misma del lazo social, y el surgimiento de nuevas formas de su representación social de las estructuras y vínculos sociales -en una perspectiva aun balbuciente de secularización- ${ }^{18}$.

${ }^{17}$ Cf. como referencia general el texto de principios del siglo XX de Ferdinand Tonnies, Community and Society. New York, Harper Torchbooks, 1963 -el original en alemán-. Tonnies presenta en esta obra una de las visiones más estilziadas y deshistorizadas de la manera como los sociólogos transforman una realidad histórica en una "oposición modélica". Sobre el mismo punto -y de la misma época- puede verse la aún más estilizada y des/historizada visión -por el objeto de su exposición y por su propia idea del "método sociológico"-, es la presentación de Émile Durkheim, en La división del trabajo social. Madrid, AKAL, 1982.

18 Para el modelo general de ese tipo de interdependencia que designamos como "sociedad de individuos" cf. Louis Dumont, Ensayos sobre el individualismo. Una perspectiva antropológica sobre la ideología moderna [1983]. Madrid, Alianza Editorial, 1987. Anterior a Dumont y sin el repetido problema formalista que ajena a algunas de las importantes obras de ese autor, cf. Norbert Elias, La sociedad de los individuos. Barcelona, Península, 1990, que sintetiza el punto de vista que Elias ya había expresado en 1965 en La sociedad cortesana -en castellano México, FCE, 1982-, cuya elaboración inicial es de c. 1930. 


\section{Los textos del viajero}

Una dificultad para abordar los textos de Francisco José de Caldas que mencionamos, tiene que ver con su extensión, y ello a pesar de cierta sistematicidad que hay en sus descripciones. Se trata de por lo menos calculando por lo bajo- de unas doscientas páginas, cuando las contemplamos hoy impresas y en su desordenada presentación habitual, páginas que cumplen de manera cuidadosa con un programa de descripción del orden natural y social que fue típico de los viajeros naturalistas del siglo XVIII ${ }^{19}$.

Desde luego que Caldas se repite en muchas oportunidades en sus textos, pero por fortuna sus descripciones tienen una fuerte dirección empírica, se atan a un lugar, a una localidad determinada, no son simplemente generalizaciones vacías, se alimentan siempre de la observación, de la conversación, de las interacciones con gentes "nobles y plebeyas" de su sociedad - para usar su terminología-; son observaciones que saben individualizar, lo que les da una indudable riqueza concreta, difícil de subsumir en un modelo sociológico abstracto, aunque las rejillas de construcción (del tipo civilización / progreso, simple / complejo, cristiano / pagano...) son fácilmente visibles, sin que tales rejillas hagan desaparecer -con algunas excepciones-la riqueza de lo concreto, que es por lo demás lo más valioso de estas páginas, las que de otra manera no resultarían de mucho interés. Es claro que las observaciones de Caldas en bastantes oportunidades expresan prejuicios de época -de la más diversa índole-, y no queda duda de que muchos de sus análisis se construyeron sobre formas de comprensión cuyas limitaciones etnocentristas hoy conocemos con toda claridad. Pero no hay duda de que casi siempre, con pocas excepciones, se trata de juicios complejos, de reflexiones que son muestra de intentos de pensar sobre problemas de la sociedad, muchos de los cuales siguen siendo objeto de interrogación importante para las ciencias sociales de hoy.

En una palabra, y esto es posiblemente lo más importante, los textos de viajero Francisco José de Caldas, casi siempre muy localizados espacial y temporalmente, son complejos y llenos de matices, y con ellos no se puede proceder a la manera de "una pesca de citas" que corroboren una determinada posición, siendo lo importante más bien restablecer el sentido de conjunto de sus afirmaciones, prestando atención a su contexto. Esa "pesca de citas" ha sido un "método" muy frecuente entre quienes se interesan en Colombia por el estudio de la obra y trabajos de Caldas, posiblemente porque al tratar con los textos de quien es uno de los héroes por antonomasia de la Independencia nacional y de su panteón de ciencia y patria, la lectura se hace difícil por la presión de un

\footnotetext{
${ }^{19}$ Este punto de unas relaciones de viaje que son al tiempo una descripción de la naturaleza, de la sociedad, la política y la cultura, es repetido varias veces por Caldas cuando trata de definir ante Mutis y Pombo los propósitos de su viaje, en repetidas comunicaciones.
}

Araucaria. Revista Iberoamericana de Filosofía, Política y Humanidades, año 19, n 38. Segundo semestre de 2017. Pp. 369-391. ISSN 1575-6823 e-ISSN 2340-2199 doi: 10.12795/araucaria.2017.i38.17 
conjunto de representaciones que existen previas al trabajo del investigador, y que terminan imponiéndose como resultado de lectura, perdiéndose toda oportunidad de una lectura no repetitiva, imaginativa, creadora...

Pero se puede tratar también de los efectos de una lectura perezosa, encantada con el camino de la repetición y poco interesada en abordar con espíritu crítico textos que a su complejidad unen su extensión y un lenguaje que por muchos aspectos no es el nuestro -recordemos que se trata de varios cientos de páginas, muchas veces presentadas bajo las peores condiciones editoriales, en donde se suman veces erratas, equivocaciones y lagunas de transcripción, ausencia de advertencias sobre los contextos de enunciación, y una fragmentación de los textos que puede ser el peor enemigo de su lectura.

Una manera de enfrentar - con riesgos desde luego- el obstáculo recién citado: la extensión y prolijidad de los textos del viajero y explorador, es partir de algunas de esas páginas que se ofrecen a manera de una síntesis concentrada, en función del problema que previamente nos hemos planteado, aunque el procedimiento puede abrir la puerta de la simplificación, siempre manteniendo la idea que anima nuestro breve análisis: que las páginas que sobre Quito escribió Caldas, páginas redactadas en el momento en que su viaje empieza a concluir, pueden ser ilustrativas para nuestros propósitos de estudiar el problema de la correlación entre la crítica de las formas sociales de vida y las formas de ruptura con el pensamiento dominante en su sociedad, uno de los elementos más dramáticos de la existencia de los Ilustrados.

Pero antes de comenzar advirtamos también sobre una objeción más que con cierta razón se puede presentar a este análisis, una objeción que señale indique que en nuestro análisis se pasa con demasiada facilidad, sin mediaciones de ninguna naturaleza y sin aviso al lector, de la consideración de los textos de Caldas a la adscripción de las posiciones críticas ahí presentes como si correspondieran al conjunto de los Ilustrados, como si Francisco José de Caldas, más allá de su nombre propio, fuera un "representante típico" de los Ilustrados neogranadinos.

En realidad no se trata de ello y no pretendemos convertirlo en un "representante típico" de un movimiento cultural, no pretendemos hacer de él la figura que "cifra y encierra" "todo" lo que los Ilustrados neogranadinos pensaban o imaginaban. Caldas es, desde nuestro punto de vista, sencillamente un miembro destacado de lo que hemos definido desde años atrás como "una comunidad de interpretación", una comunidad en cuya conformación Caldas jugó un visible papel directivo, convirtiéndose en el transcurso de pocos años en maestro de formación de sus propios condiscípulos, liderando algunas de sus publicaciones -entre ellas el Semanario del Nuevo Reino de Granada, la principal publicación del grupo en el campo de la actividad de ciencia-, al tiempo que sus compañeros mostraban una gran consideración por él y por su 
trabajo, trabajo que había sido un elemento central en su proceso de inmersión en la "ciencia moderna". Es eso lo que permite hacer esa asimilación, que de otra manera sería criticable y que aquí no quiere decir que caldas es ni "expresión" ni "reflejo", sino figura central en la elaboración de una forma de pensar y de identidad.

Partamos pues sin más demoras al análisis de esas páginas que escribió Caldas al final de su productiva estancia en el Reino de Quito, y en la ciudad de Quito, reino y ciudad en donde por lo demás lo trataron muy bien, y en donde nunca se sintió extraño, en un periodo de su vida que fue central en su experimentación de terreno y en su afirmación en el método crítico, la base de formación de lo más consistente de su saber botánico y geográfico, al tiempo que lugar en donde construyó su visión de las sociedades andinas.

\section{El arte de Quito en los relatos de Caldas en 1804-1805}

El fragmento a que nos referimos se titula "Viaje de Quito a Popayán", aunque la titulación puede ser del editor, pero ese dato es ahora secundario. Como lo hacía con todas las poblaciones y ciudades por donde pasaba, Caldas, que a estas alturas conocía ya bien la ciudad de Quito y toda su periferia, emprende un balance sobre sus infraestructuras materiales, sobre el estado de sus calles, sobre el crecimiento de su población, sobre la calidad del agua, sobre el consumo de alimentos, y cierra sus consideraciones con algunas observaciones sobre el arte y la arquitectura. Sólo éstas últimas son las que nos interesan ahora. Como son breves, podemos citarlas en extenso, no para valorarlas, ni ponernos a favor o en contra de ellas, sino para contextualizarlas y tratar de acercarnos a lo que puede ser una interpretación razonable de esas observaciones, repetidas de diferentes maneras en sus relatos de viaje, hablando de otras ciudades y pueblos, a propósito de los mismos o de otros elementos de civilización material y de vida espiritual, y que son observaciones que tanto han molestado a sus lectores desde el siglo XIX hasta el presente, al punto que los editores de sus obras, como Acosta en el siglo XIX, y Barreiro para las Relaciones de viaje, se han sentido en la necesidad de incluir pies de páginas, corrigiendo las apreciaciones de Caldas sobre las artes en Quito.

\footnotetext{
“Artes. Las artes en general se hallan en un estado de desgreño y de rusticidad, y en muchas de ellas le hacen ventaja las ciudades subalternas. La escultura de que se gloria Quito, en que ocupa tantas manos, y que provee de efigies, está en un estado bien miserable. Los artistas, sin principios, sin genio, son unos serviles imitadores de lo que hicieron sus mayores. San Antonios con un niño sobre un libro, Santo Domingos con el perro, ángeles en éxtasis, la boca media abierta y con una barra de lacre en las manos, son todos los esfuerzos de
} 
nuestros Fidias. Esto vieron hacer, esto hacen, y ¿quién es capaz de sacarlos de estos usos? La pintura corre la misma suerte. Eternos imitadores, no forman un dedo de su propio fondo. El que más se eleva, aquel que más se cree al nivel de Rafael, de muchas piezas forma una. A pesar de estos grandes defectos, existe Samaniego, que pinta con regularidad, y aunque servil por timidez y por hábito, tiene gusto en la elección que hace, y mucho más en el colorido. Pero, ¡cuánto le falta para ser pintor! La arquitectura no puede gloriarse ni de albañiles. Es cierto [que] tiene buenos trozos antiguos que manifiesta que los hubo inteligentes; pero no dejaron semilla. Todo edificio posterior es un monstruo que deshonra al artista y al gusto de sus dueños. El arte del tirador y lamista, o galonero, se halla en un estado regular de perfección. Es de un inmenso consumo su producto en los faldellinos de las mujeres. Pero la moda comienza a variar, y ese montón de manos ocupadas en este arte de puro lujo, están amenazadas de perecer. Un ejemplo funesto tiene en los rengueros. El carpintero, el ebanista, platero, herrero, etc., etc., se hallan en un pie demasiado grosero. Las artes de sastrería y zapatería, etc., no tanto como los primeros" ${ }^{20}$.

Examinemos con cuidado este texto, centrado en un punto preciso: el del arte y la arquitectura, y sus artífices y operarios. Texto muy concentrado desde el punto de vista del sentido. Breve en su argumentación y cerrado en sus conclusiones, excepción hecha de uno u otro matiz; y que parece mostrar de forma sintética una argumentación y veredicto que son repetidos, palabras más palabras menos, en otras partes de los relatos de viaje de Francisco José de Caldas, cuando se trata de evaluar las sociedades andinas que recorrió en su viaje como explorador botánico, experto en geografía y sabio en astronomía, con el mecenazgo de José Celestino Mutis y del comerciante ilustrado afincado en Cartagena, José Ignacio de Pombo, según lo advertimos más arriba.

El viajero que ha peregrinado por el Reino de Quito y que conoce bien la ciudad de Quito (sus iglesias, sus construcciones civiles, los tipos de vivienda, las costumbres, etc., como lo sabemos por sus descripciones) arranca con una aparente condena general de esa "actividad artística", y de otros oficios artesanales complementarios, aunque acota sus observaciones de manera explícita a la ciudad de Quito ${ }^{21}$.

${ }^{20}$ En Relación de un viaje hecho a Cotacache, la villa de Imbabura, Cayambe, etc., comenzado el 23 de julio de 1802, por Francisco José de Caldas - publícalo por primera vez el P. Agustín Barreiro, O.S.A., de la Academia de Ciencias Exactas, Físicas y Naturales-. Madrid, Librería General de Victoriano Suárez, 1933, pp. 204-205 para la parte citada. La Relación de un viaje a Cotocache... cuenta con una edición fotostática, realizada por el Consejo Superior de Investigaciones en Madrid -2013-, a cargo de Reinhard Andress, acompañada de textos del mencionado Andess y de Mauricio Nieto.

${ }^{21}$ Hay que recordar que Caldas habló varias veces de Quito, y puso de presente la importancia de algunas de sus construcciones civiles y religiosas, e hizo elogios de la Biblioteca Real de la ciudad, pero este es el único texto en que se concentró de manera específica en el arte y los artistas de la ciudad. 
Para empezar por el final del texto de Caldas, podemos recordar que los oficios estrictamente artesanales de la carpintería, la ebanistería, la platería y la herrería le parecen encontrarse en un "estado demasiado grosero", aunque reconoce que otras actividades como las de sastre y de zapatero pueden mostrar algunos logros. Y en cuanto a oficios complementarios, mucho más cercamos a la actividad propiamente artística, como los de laminador, tirador o galonero, Caldas declara que se encuentran "en un estado de regular perfección".

Es claro esta breve observación plantea muchos problemas, empezando por el de su exactitud, y luego el de su historicidad, pues Caldas registra un momento de una evolución, toma una fotografía, como cualquier otro etnógrafo, pero no describe la situación como un proceso. Por lo demás, el proceso histórico y el significado cultural de los obrajes, de las pequeñas factorías de producción de objetos de consumo que no se traían de fuera, pero que ya no eran del orden estricto de la producción doméstica, sigue siendo un objeto abierto a la investigación, como lo es el problema de la forma como el reformismo borbónico del último tercio del siglo XVIII modificó el estado de ese tipo de trabajo y producto, o por lo menos quiso modificarlo -por fuera de que "las artesanías de Quito", siguen siendo hasta el presente un objeto de admiración, de quienes visitan la ciudad, y se acercan a los talleres y/o mercados artesanales ${ }^{22}$.

Pero la condena más severa de la actividad de arte y artesanía en la ciudad de Quito se encuentra en los primeros renglones del texto que hemos citado, y no tiene tanto que ver tanto con las artesanías, los obrajes y los oficios artesanales -es decir el trabajo material subordinado-, sino con el arte y la arquitectura de la época.

En esas páginas Francisco José de Caldas comienza hablando de las "Artes" en Quito, y nos introduce, si leemos con cuidado, en lo que puede designarse como el "sistema de las artes en los finales del siglo XVIII", es decir la escultura, la pintura y la arquitectura ${ }^{23}$. En tono muy crítico Caldas comienza hablando de la escultura quiteña, al parecer la más generalizada de las artes

${ }^{22}$ Las actuales guías de turismo, pero no menos las historias del arte en la época de la sociedad colonial en Quito, regularmente son elogiosas al hablar de sus artesanos y artistas, un elogio que además parece ser una representación social extendida, y no sólo una opinión de críticos calificados o de observadores interesados. Al respecto cf. muchas de las obras incluidas en el importante catálogo del Fondo de Salvamento del Patrimonio Cultural, por ejemplo Ximena Escudero Albornoz, Púlpitos quiteños. La magnificencia de un arte anónimo. 2004. Como referencia simplemente panorámica, pero que por ello mismo ofrece algunos elementos comparativos cf. Gauvin Alexander Bailey, Art of Colonial America. London/New York, Phaidon, 2005.

${ }^{23} \mathrm{La}$ indicación de caldas es precisa y debe reflejar bien la clasificación de las artes de finales del siglo XVIII. Pero no hay que concluir demasiado pronto sobre este punto, pues es muy poco lo que sabemos sobre asuntos de esta naturaleza: la investigación nacional sobre el "arte en la sociedad colonial" ha tomado como una de sus normas permanentes la de imponer a esa sociedad nuestras caracterizaciones actuales del "arte y el artista", y poco o nada se ha preocupado por interrogarse sobre la forma como la época pensaba ese tipo de problemas. 
(la que más manos emplea, dice Caldas), ocupada en satisfacer una demanda constante de efigies, cuyo carácter de imágenes religiosas indica renglones adelante y que considera como una producción en "estado miserable" 24 .

Caldas designa a esos productores de "efigies" con el vocablo preciso de artistas -una palabra particular que pone de presente la existencia reconocida en esa sociedad de una categoría social específica relativamente separada del mundo artesanal, aunque no disponemos de ninguna genealogía siquiera inicial del proceso histórico de redefinición de esa categoría en el marco específico de las "sociedades coloniales americanas"-, y caracteriza esa producción artística como dominada por la imitación de sus modelos, realizada por artistas "sin principios, sin genio", incapaces de remontar el horizonte "de lo que hicieron sus mayores".

De manera aún más precisa, a través del ejemplo, y como si tuviera al frente esas efigies que critica, Caldas escribe, como ya citamos, que: "San Antonios con un niño sobre un libro. Santo Domingos con el perro. Ángeles en éxtasis, la boca media abierta y con una barra de lacre en las manos, son todos los esfuerzos de nuestros Fidias"; para rematar de manera concluyente: "Esto vieron hacer, esto hacen, y quien puede sacarlos de ahi' ${ }^{25 * *}$.

Al ilustrado neogranadino le parece que la situación de la pintura no difiere de aquella de la escultura, pues se trata, en su opinión, de "eternos imitadores", que "no forman un dedo de su propio fondo", esto es, que no tienen ninguna imaginación artística propia, agregando que algunos de ellos, sin dejar de creerse en el nivel de Rafael, de muchas piezas no forman más que una, es decir que no pasan de la imitación ecléctica de piezas sueltas de una herencia clásica que Caldas parece apreciar, como se nota por su mención de Rafael, pero con la cual nada nuevo se produce en el caso del arte de Quito. La única excepción que encuentra Caldas en ese panorama es la del conocido pintor quiteño de finales del siglo XVIII y principios del siglo XIX, en actividad en la época en que Caldas se encuentra en Quito, Manuel Samaniego (1767 - 1824), en quien reconoce colorido, una actividad artística constante y recreación de los temas tradicionales, aunque lamenta que el hábito y la timidez lo paralicen, lo que le impide ser un verdadero pintor $^{26}$.

${ }^{24}$ El carácter de arte de las imágenes religiosas en esa precisa sociedad es también un punto en discusión. Pero hay que advertir al lector, para evitar todo contrasentido, que para una sociología que se afirma en las ciencias sociales, nuestra observación no representa una valoración del autor de este texto, sino una pregunta sobre el sistema clasificatorio y valorativo de esa sociedad. Una clarificación muy importante de este problema en Hans Belting, Imagen y culto. Una historia de la imagen anterior a la historia del arte [1990]. Madrid, AKAL, 2009.

${ }_{25}^{* *}$ Subrayado nuestro.

${ }^{26}$ Manuel Samaniego y Jaramillo (1767-1824), es un importante pintor quiteño, autor de obras tanto "religiosas" como "seculares", que no solo obtuvo contratos importantes en su época con algunas iglesias y mecenas, sino que mantuvo con buena suerte un taller y tuvo discípulos que se hicieron a su propio nombre. La bibliografía y el tema son amplios, sobre todo si se quiere observar las relaciones a finales del siglo XVIII entre el artista y el artesano. Cf. por ejemplo Alexandra Kennedy Troya - 
En cuanto a la arquitectura, una actividad aun menos individual que la pintura, con una división del trabajo mejor establecida y con una jerarquía social de oficios muy reglamentada, el juicio no es menos rotundo, pues hasta la parte baja de la cadena sale criticada, ya que Caldas ni siquiera encuentra buenos albañiles. Le parece sí que hay huellas materiales que son prueba de que en el pasado algunas obras de valor se hicieron, "pero no dejaron semilla", y lo que en tiempos recientes se ha hecho "es un monstruo que deshonra al artista y al gusto de sus dueños", palabras que ponen de presente una interpretación que fue constante entre los Ilustrados del Nuevo Reino de Granada, por la cual condenan su presente inmediato e idealizan ciertos momentos anteriores del siglo XVIII, bien se trate de aquellos de las exploraciones científicas de finales de la primera mitad de siglo -c. 1735-, o de los años 1760, cuando ya hay ecos de las reformas borbónicas en el campo de la educación y de la "actividad de ciencia" y que en el virreinato de Nueva Granada coincide con la llegada del médico-botánico José Celestino Mutis, lo que hace que el llamado "tiempo de la Ilustración" tenga la forma contradictoria y simultánea de una novedad radical y de un renacimiento de historias pasadas.

Nos encontramos pues, como balance, con una crítica radical, realizada por un hombre de letras moderno, que parece no complacerse ni identificarse con nada de lo que encuentra en su entorno, como si las formas de creación artística que lo rodean no constituyeran ya para él un lenguaje que mereciera alguna admiración y en que pudiera reconocerse. Para Caldas se trataría ante todo de imitación servil, de hábitos de trabajo y maneras de hacer que se reproducen de una generación a otra sin cambio alguno. La idea de Caldas es, pues, la de que se trata de actividades poco creativas, por el hecho mismo de que se inscriben en una lógica de la repetición ${ }^{27}$.

\section{Razones y significado de un equívoco}

Sobre estas líneas escritas por Francisco José de Caldas se han hecho en el pasado varios comentarios, empezando por los del propio editor inicial de las obras del naturalista neogranadino en el siglo XIX, quien inauguró una tradición que luego no ha hecho más que repetirse. Según Don Joaquín Acosta:

editora-, Artes académicas y populares del Ecuador. Quito, Abya-Yala/Fundación Paul Rivet, 1995.

${ }_{27}$ Tomo la idea de Freud pero alteró su significado y alcances. Aquí la idea de repetición no remite a un tipo de compulsión que nos regresa al pasado y aun a un pasado doloroso, sino que remite de manera más simple a un peso especifico de la tradición -una tradición vinculada a formas específicas de relaciones sociales-, que obstruye o por lo menos dificulta todo proceso de innovación. Para el sentido propiamente psicoanalítico de la noción cf. Sigmund Freud, Más allá del principio del placer [1920], en Obras Completas, 3. Madrid, Biblioteca Nueva/El Ateneo, 2008. 
Quito ha pasado siempre con razón, como la ciudad de América en donde las artes de imitación se desarrollaron más y es injusta la crítica y exagerada la exigencia de Caldas $^{28}$.

Las palabras recién citadas historiador Joaquín Acosta en su tarea de edición de las "obras" de Caldas, no dejan de ser reveladoras. En primer lugar ponen de presente su idea del arte como imitación, es decir como reproducción directa de los objetos reales, aunque Acosta no percibe que tal imitación tiene necesariamente que apoyarse en los modelos conocidos-los de la tradición-, antes que en los objetos que se observan, si se tiene en cuenta que la producción de "efigies" no puede dejar de inscribirse en "formas de hacer" que constituyan un lenguaje reconocido por sus "usuarios", si se quiere que sean un lenguaje con significado social.

Dicho en otras palabras, debe recordarse que el artista no puede dejar de dialogar con su propia historia y tradición, que en este caso no podría ser otra que la de las imágenes sagradas que reproducían modelos canónicos (es decir modelos que sean al mismo tiempo compartidos, impuestos y legítimos), sin que existiera aun, por simple imposibilidad histórica, un conjunto plural de tradiciones que obrara como un horizonte abierto de posibilidades, precisamente porque no se trataba de una sociedad moderna, sino de una sociedad que, en sus medios urbanos y de manera muy minoritaria, trataba de moverse en una dirección que nosotros hoy designamos con ese término sociológico a veces no bien definido de sociedad moderna ${ }^{29}$.

Don Joaquín Acosta dice también, y esto es realmente importante, que las exigencias de Caldas son exageradas, o dicho en nuestras palabras, que los modelos artísticos a partir de los cuales realiza su crítica son anacrónicos $-\mathrm{y}$ se podría agregar que etnocentristas-, como se nota en su invocación de Fidias y de Rafael, como ideales en el campo de la escultura, lo que puede ser visto por algunos como una imposición de la Antigüedad y del Renacimiento como cánones que el pensamiento ilustrado definía como una tradición insuperable, según las definiciones del llamado Neoclasicismo, a la que la actividad artística, sin excepción, debería someterse ${ }^{30}$.

${ }^{28}$ Cf. Francisco José de Caldas, "Viaje de Quito a Popayán", en Obras de Francisco José de Caldas. Bogotá, Universidad Nacional de Colombia, 1966, pp. 519-525. El cura Barreiro, el editor de la Relación de viajes, hace los mismos reparos críticos a Caldas, cf. Agustín Barreiro, Relación de un viaje... op. cit.

${ }^{29}$ El carácter innovador y el horizonte abierto y de libertad que caracteriza a la pintura de la época de la Ilustración en Europa es puesto de presente y argumentado por Tzvetan Todorov en La pintura de la Ilustración: de Watteau a Goya. Barcelona, Galaxia Gutenberg, 2014. Cf. igualmente, Museo Nacional del Prado, Goya y el espíritu de la Ilustración-Catálogo-. Madrid, Banco Central, 1988.

${ }^{30}$ La presencia y la alta valoración de la Antigüedad y el Renacimiento como ideales artísticos en la pintura ilustrada, un hecho conocido, es puesta de relieve en el libro recién citado de Tzevetan Todorov, La pintura de la Ilustración, op. cit., "El espíritu de la Ilustración”, pp. 14-17. 
Siguiendo la lógica de análisis del historiador Acosta diríamos que el caso de Caldas y el de los Ilustrados recuerdan una situación en la que, supuestamente, se enfrentan unas convenciones (en este caso la estética de los Ilustrados) contra la cultura. Una situación en que las convenciones de la producción artística, definidas por un grupo determinado e impuestas al conjunto de la sociedad desde mucho tiempo atrás, se han constituido en un patrimonio y en una condición de inteligibilidad, por lo que son consideradas como las únicas legítimas, y al parecer de pronto se encuentran desafiadas por la aparición en la escena de un grupo social "innovador", portador de nuevas normas de hacer y de pensar en una dominio determinado, y aparecen a la sociedad mayoritaria, portadora de esos valores establecidos, como la expresión de maneras de hacer y de decir que desafían una tradición que, por su permanencia en el tiempo, ha sido naturalizada -como lo pensaba el historiador Acosta, que no puede entender las opiniones de Caldas, y las estima como inapropiadas e injustas.

La expresión "convenciones contra la cultura" es del historiador Germán Colmenares, y muy poco se ha hecho por interpretar su significado. De manera básica ésa idea de "convenciones contra la cultura", perteneciente en mi opinión al campo del nacionalismo historiográfico, ha estado muy presente en el análisis del problema de la Ilustración y la Modernidad a lo largo del siglo XX en Hispanoamérica ${ }^{31}$, y es una idea que hasta el presente sigue siendo dominante en nuestro medio, tal como lo muestra su recepción-disfrazada, metaforizada- por la crítica postmoderna de la Ilustración, que acusa a ésta y a los Ilustrados de haber asumido sin ninguna discusión las perspectivas europeas sobre el arte y la sociedad.

Volvamos a recordar que Caldas menciona a Fidias y a Rafael, como modelos, y que ello se ha interpretado de manera reciente -desde finales del siglo XX- como una crítica de las tradiciones culturales consideradas "autóctonas", "ancestrales" de las "regiones periféricas de Europa", una crítica que pondría de presente la forma como el colonialismo y el eurocentrismo (aliados siempre), imponen desde hace más de dos siglos una "lectura" sesgada de la vida cultural de las zonas "no occidentales del mundo", ese "otro mundo", siempre ignorado y maltratado, según esa lógica de razonamiento ${ }^{32}$.

Habría sin embargo que examinar con cuidado esas respuestas que han inspirado tantos consensos en años recientes y que, como anotamos, restituyen el viejo "nacionalismo historiográfico", cubierto ahora con una retórica renovada,

\footnotetext{
31 Cf. G. Colmenares Las convenciones contra la cultura. Ensayos sobre historiografia hispanoamericana del siglo XIX [1986]. Bogotá, Tercer Mundo editores, 1997.

${ }_{32}$ Para una síntesis de los argumentos repetidos contra la Ilustración, incluidos los recientes de los postmodernos, bajo sus formas más sofisticadas o bajo las versiones más simplistas y a veces burdas, y para la crítica que puede y debe hacerse de tales argumentos cf. Anthony Pagden, La Ilustración y por qué sigue siendo tan importante para nosotros [2013]. Madrid, Alianza editorial, 2015
}

Araucaria. Revista Iberoamericana de Filosofía, Política y Humanidades, año 19, n 38. Segundo semestre de 2017. Pp. 369-391. ISSN 1575-6823 e-ISSN 2340-2199 doi: 10.12795/araucaria.2017.i38.17 
y tratar de plantearse de nuevo el problema, pero en otros términos, partiendo del reconocimiento de un hecho social que no resulta difícil de constatar y que sociológicamente ha sido analizado en múltiples oportunidades: la evolución desigual y plural de los diferentes grupos que conforman esa abstracción que llamamos "sociedad" 33 . Es posible que los Ilustrados neogranadinos se encontraran en una fase de descubrimiento de nuevas formas de actuar, sentir, pensar y representar, y en proceso de afianzar una percepción nueva del mundo, que para ellos va a terminar convertida incluso en una forma de identidad, y no parece el mejor camino de análisis condenar el descubrimiento que realiza un grupo cultural, de un nuevo horizonte de posibilidades, en términos del pasado y de la fidelidad a las formas tradicionales de representar.

Sobre la base de esa perspectiva habría que reconocer que en América hispana los Ilustrados, tanto o más que en Europa, pertenecen a una comunidad intelectual que intenta separarse, a veces de manera abrupta, del pasado y de las tradiciones de su medio social, dando lugar a una ruptura cultural que los mostrará, pero tan solo en apariencia, como ajenos al resto de la sociedad, aunque esa sociedad siguió siendo siempre uno de sus mayores objetos de reflexión.

Ese proceso de separación no constituye un ejercicio aristocrático de distinción ni un esfuerzo de creación de barreras sociales artificiales. Es, por lo menos en este caso, un proceso socio-histórico, producto de grandes transformaciones acumuladas por la sociedad, un proceso que produce como efecto objetivo, no buscado, una línea de separación, que nos recuerda que, desde mediados del siglo XVIII, y en el marco de las transformaciones de la monarquía, un grupo social minoritario, pero importante culturalmente y distintivo de esa sociedad concreta, venía participando en la construcción de una visión nueva sobre la sociedad, una visión que incluía nuevas ideas sobre las bases del vínculo social, sobre las relaciones entre lo sagrado y lo profano, sobre la valoración de la naturaleza, y ello en la perspectiva de un horizonte abierto, al que denominaban progreso y civilización, horizonte que desembocaba en la idea de un futuro posible al que identificaban con una forma nueva de tiempo histórico abierto y lineal, que se relacionaba con el crecimiento de la riqueza material y espiritual, y con la misma felicidad, y que designaban con la expresión, tiempo de la Ilustración.

En términos de análisis sociológico, antes que hablar de convenciones contra la cultura o de una visión enajenada de la sociedad, o de una simple

\footnotetext{
33 Esa evolución desigual adquiere aun caracteres más notables en el caso de los Ilustrados neogranadinos -lo que me parece que es común a las demás sociedades andinas-, por el carácter en extremo minoritario del movimiento ilustrado en estas sociedades - es por eso que hace no mucho recurrí a la expresión "archipiélago ilustrado", para describir su carácter fragmentado, aislado y no siempre en conexión constante: Una comunidad de interpretación que difícilmente encontraba elementos suficientes de cohesión social para animar e impulsar el desafío cultural que intentaba plantearle a su sociedad. Sobre el "archipiélago cultural" cf. R. Silva, Cultura escrita, historiografia y sociedad en el virreinato de la Nueva Granada. Medellín, La Carreta Editores, 2015.
} 
reproducción de las formas "eurocéntricas" de observar la "realidad propia", lo que habría que recordar es, ante todo, que "por debajo" de esas nuevas visiones de la sociedad, lo que se mueve es un mundo en transformación, que está dejando de ser el viejo orden imaginado al comienzo de la conquista y colonización por el poder monárquico, y que lo que ahora parece abrirse paso es una nueva forma de categorizar y representar la sociedad, una manera nueva de pensar el tiempo histórico, una visión que avanza en el propósito de abandonar la idea de la existencia social como destino de repetición ${ }^{34}$.

En cualquier caso, la crítica de Caldas a las artes en Quito nos recuerda que, como lo afirmamos desde el principio de estas líneas, el pensamiento y la actividad intelectual pueden producir siempre distancia frente a la comunidad, y por lo tanto extrañeza y alejamiento, como ya Platón lo había puesto de presente respecto de su propia sociedad. Es una idea que vale la pena ser discutida, en una época de tanta demagogia y populismo. Y respecto del análisis histórico de la Ilustración y de los ilustrados, es un punto que debería tenerse en cuenta antes de condenarlos como una "élite social" que "despreciaba a las clases subalternas", tratando más bien de evaluar las condiciones históricas en que se produjo ese inicial acceso a la modernidad de una sociedad de individuos, sin olvidar nunca la regla de análisis histórico que exige comprender las actividades humanas en el que contexto de época, lugar y circunstancias, como enseñaban los viejos manuales.

${ }^{34}$ Como debe recordarse que una parte de la sociedad había comenzado a recorrer ese camino, como lo pone de presente Caldas en su texto, cuando habla de la presencia en la sociedad quiteña de la moda, como un elemento nuevo, una mención que ha propósito hemos dejado de lado, pero sobre la que podemos recordar que es uno de los más seguros indicios de la existencia de la forma de tiempo nuevo y fugaz que caracteriza las sociedades modernas. Igualmente el proceso puede abordarse a partir de la relación con el dinero, la aspiración a formas sofisticadas de consumo, la valoración del comercio y la idea de necesidades sociales e individuales que se reproducen de manera constante, hechos todos constatables en los textos de Caldas y que los Ilustrados encerraron en una fórmula precisa: progreso y felicidad, un emblema del que pensaban ser los portadores. 


\section{Referencias bibliográficas:}

Academia Colombiana de Ciencias Exactas, Físicas y naturales, Cartas de Caldas. Bogotá, Imprenta Nacional, 1978.

Bailey, Alexander Gauvin, Art of Colonial America. London/New York, Phaidon, 2005.

Belting, Belting, Imagen y culto. Una historia de la imagen anterior a la historia del arte [1990]. Madrid, AKAL, 2009.

Caldas -1768-1816. Bogotá, Molinos Velásquez Editores, 1994

Caldas. Bogotá, Universidad de los Andes/CESO/ICANH/, 2006.

Chartier, Roger, "Trayectorias y tensiones culturales en una sociedad de Antiguo Régimen", en Jacques Revel y André (directores), Histoire de la France, T. III. Les formes de la culture. Paris, Seuil, 1987

Colmenares, Germán (Editor), Relaciones de Mando e Informes de los virreyes de Nueva Granada,3 tomos. Bogotá, Banco Popular, 1989.

Colmenares, Germán, Las convenciones contra la cultura. Ensayos sobre historiografía hispanoamericana del siglo XIX [1986]. Bogotá, Tercer Mundo editores, 1997.

Correo Curioso, erudito, económico y mercantil de la ciudad de Santafé de Bogotá. 1801.

De Caldas, Francisco José, "Viaje de Quito a Popayán”, en Obras de Francisco José de Caldas. Bogotá, Universidad Nacional de Colombia, 1966, pp. 519-525.

Dumont, Louis, Ensayos sobre el individualismo. Una perspectiva antropológica sobre la ideología moderna [1983]. Madrid, Alianza Editorial, 1987.

Elias, Norbert, La sociedad de los individuos. Barcelona, Península, 1990,

Elliott, John H., Imperios del mundo atlántico. España y Gran Bretaña en América (1492-1830. Madrid, Taurus, 2006

Émile Durkheim, en La división del trabajo social. Madrid, AKAL, 1982.

Ferrone, Vincenzo y Roche, Daniel Roche, Editores, Diccionario Histórico de la Ilustración. Madrid, Alianza Editorial, 1998.

Freud, Sigmund, Más allá del principio del placer [1920], en Obras Completas, 3. Madrid, Biblioteca Nueva/El Ateneo, 2008.

Guerra,François-Xavier, Modernidad e independencias. Ensayos sobre las revoluciones hispánicas. Madrid, MAPFRE, 1992.

Historia documental de la Real Expedición Botánica del Nuevo Reino de Granada después de la muerte de su director, don José Celestino Mutis, 1808-1852. Bogotá, Instituto de Cultura Hispánica, 1986.

Kennedy Troya, Alexandra (editora), Artes académicas y populares del Ecuador. Quito, Abya-Yala/Fundación Paul Rivet, 1995. 
Levine, Lawrence, Highbrow/Lowbrow. The Emergence of Cultural Hierarchy in America. Harvard University Press, 1988,

Michel Foucault, Sobre la Ilustración. Madrid, Tecnos-Clásicos del pensamiento-, 2003

Museo Nacional del Prado, Goya y el espíritu de la Ilustración-Catálogo-. Madrid, Banco Central, 1988.

Nieto Olarte, Mauricio [et al.], La obra cartográfica de Francisco José de

Pagden, Anthony, La Ilustración y por qué sigue siendo tan importante para nosotros [2013]. Madrid, Alianza editorial, 2015

Passeron, Jean-Claude / Revel, Jacques, "Penser Par Cas", Enquête, No 4. , Paris, EHESS, 2005.

Pérez Arbeláez, Enrique, Humboldt en Colombia [1959]. Bogotá, COLCULTURA, 1982,

Phelan, John Leddy, El pueblo y el rey: la revolución Comunera en Colombia, 1781 [1974]. Bogotá, Carlos Valencia Editores, 1980.

R. Silva, Prensa y Revolución. Bogotá, Banco de la República, 1988.

Silva R., Cultura escrita, historiografía y sociedad en el virreinato de la Nueva Granada. Medellín, La Carreta Editores, 2015.

Silva, R., Saber, Cultura y Sociedad en el Nuevo Reino de Granada. Siglos XVII y XVIII [1984]. Medellín, La Carreta Editores, 2012.

Silva, Renán, La Ilustración en el Virreinato de la Nueva Granada. Estudios de historia social y cultural. Medellín La Carreta Editores, 2005, y R. Silva, Los Ilustrados de Nueva Granada, 1760-1808. Genealogía de una comunidad de interpretación [2002] Medellín, Banco de la República/ EAFIT, 2008 -segunda edición-.

Todorov, Tzvetan, La pintura de la Ilustración: de Watteau a Goya. Barcelona, Galaxia Gutenberg, 2014.

Todorov, Tzvetan, El espíritu de la Ilustración. Barcelona, Círculo de Lectores / Galaxia Gutenberg, 2008.

Tonnies, Ferdinand, Community and Society. New York, Harper Torchbooks, 1963

Vovelle, Michel y otros, El hombre de la Ilustración [1992]. Madrid, Alianza Editorial, 1995. 
